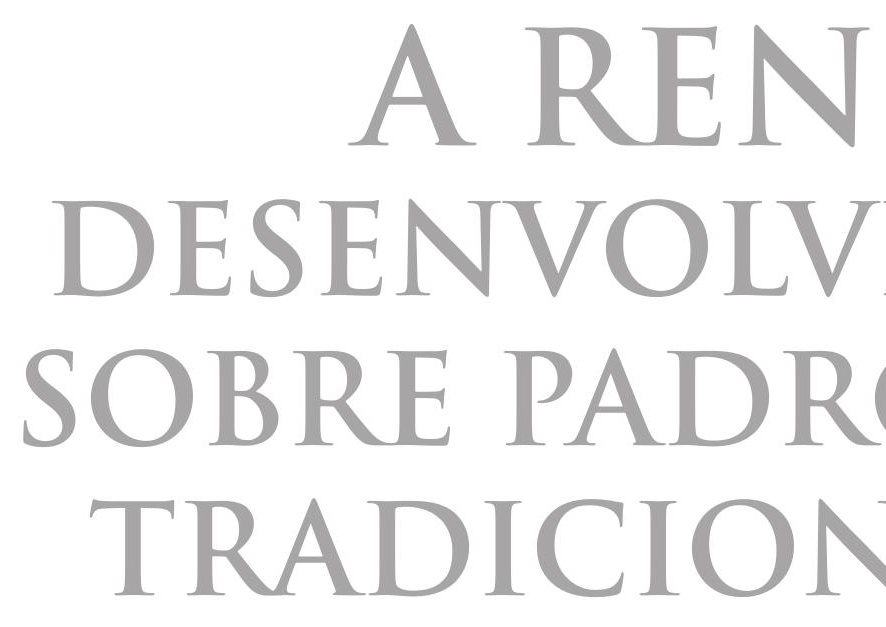




\section{A RENDA DESENVOLVIDA SOBRE PADRÕES TRADICIONAIS}

J ACKSON B O UERES DAMASCENO JÚN I OR

UNIVERSIDADE ESTADUAL DO MARANHÃO

RUMI REGINA KUBO

UNIVERSIDADE FEDERAL DO RIO GRANDE DO SUL 


\title{
A RENDA DESENVOLVIDA SOBRE PADRÕES TRADICIONAIS
}

\section{Resumo}

Os processos de reordenamento agrário têm influência na formação da renda das famílias de agricultores, utilizando o trabalho para articular as dimensões social e ambiental do processo, formatando um processo cultural específico evidenciado cotidianamente, permitindo avaliar a inserção de cada contexto sob a ótica do capital financeiro e a lógica da resistência à entrada do referido capital no meio rural.

Palavras-chave: reordenamento agrário, cultura, políticas públicas, reprodução social.

\section{THE INCOME DEVELOPED OVER TRADITIONAL STANDARDS}

\begin{abstract}
The agrarian reordering process has influence on the formation of the income of farming families, using the work to articulate the social and environmental dimensions of the process, formatting a specific cultural process daily evidenced, allowing to evaluate the insertion of each context under the perspective of the financial capital and the logic of resistance to the entry of the said capital in the rural environment.
\end{abstract}

Keywords: agrarian reordering, culture, public policies, social reproduction. 


\section{EL INGRESO DESARROLLADO A PARTIR DE PATRONES TRA- DICIONALES}

\section{Resumen}

Los procesos de reordenamento agrário influyen em la generación de renta de las famílias de agricultores, donde se utiliza el trabajo para articular las dimensiones social y ambiental para crear um proceso cultural específico que se evidencia cotidianamente, que permite evidenciar la inserción de cada contexto sobre la óptica del capital fincanciero y la lógica de la resistencia a la entrada de referido capital en el entorno rural.

Palabras clave: reorganización agraria, cultura, política pública, reproducción social

Jackson Bouéres Damasceno Júnior

jbagroeco@gmail.com

Rumi Regina Kubo

rumikubo2002@gmail.com 


\section{INTRODUÇÃO}

O processo de intervenção estatal por meio das políticas públicas está despertando a curiosidade de muitos pesquisadores. Inicialmente, este processo era entendido como uma forma de proporcionar a geração de renda por parte do campesinato, mas, com o avanço dos estudos outras variáveis foram introduzidas na referida discussão.

Nestes termos, foi observado que a inclusão de elementos sociais e referenciais históricos e culturais nas análises tende a fortalecer as práticas produtivas e ao mesmo tempo em que as igno$\mathrm{ra}$, fomenta o insucesso da intervenção do Estado no processo de desenvolvimento rural.

O etnodesenvolvimento incorpora diversos fatores dentro da análise do desenvolvimento, pois, entende que o desenvolvimento econômico é fruto de um processo de construção peculiar a cada grupo social específico, e que essa construção precisa ser observada na concepção das políticas públicas, elemento decisivo para o sucesso das mesmas.

Nenhum processo de desenvolvimento rural pode ser observado de fora para dentro das realidades onde estão evidenciados, pois, antes de qualquer coisa, a economia, em seu significado traz a maneira como é desenvolvido o trabalho em um ambiente específico, no mesmo sentido em que a terra para o campesinato é um meio de produção essencial para a gênese do capital.

Assim, a forma como se comportam, as políticas públicas de desenvolvimento rural são contradições clássicas das teorias fundadoras da ciência econômica e social, sendo responsável incontestavelmente pelo fracasso do modelo utilizado para analisar e formatar e implementar políticas públicas destinadas à geração de renda dos camponeses.

\section{OS COTIDIANOS E AS (DES)ECO- NOMIAS}

A relação entre a apropriação e a utilização dos recursos naturais, particularmente da terra, com o desenvolvimento das nações tem sido reconsiderada recentemente no contexto de reflexões que vêm buscando superar as reconhecidas limitações e simplificações das teorias e análises, principalmente dos economistas (Ramos 2001).

A terra como fator de produção também é encarada como elemento de acumulação primitiva do capital, apresentando nesta afirmação o primeiro paradigma deste texto (Marx et al. 1997). Embora tais reflexões levem em conta também a situação dos países desenvolvidos, elas parecem ser mais importantes quando se referem ao caso dos países subdesenvolvidos, pois, é nestes que "a terra é ainda o mais importante meio de produção" (Ramos 2001), pois, “seu estatuto é muitas vezes determinado por considerações culturais de alocação, uso e gestão ambiental" (Cuéllar 1997:45), "sendo também uma fronteira para a expansão dos padrões capitalistas de produção e consumo, ainda não incorporados pelas sociedades rurais" (Schineider 2004:90), e nos quais é necessário "uma economia e uma política renovadas" que tenham em conta a 
situação de "seus produtores agrícolas e de suas sociedades rurais" (Perroux 1981:252). Dentre as funções destinadas a terra (Sabourin 2008), a produção agrícola, ou seja, a função econômica é apenas uma delas, existindo ainda muitas outras. Polanyi (1980: 181) aborda tal problemática partindo do reconhecimento de que "a função econômica é apenas uma entre as muitas funções vitais da terra. Esta dá estabilidade à vida do homem, é o local da sua habitação, é a condição da sua segurança física, é a paisagem e as estações do ano". $\mathrm{Na}$ análise histórica que fez, constatou que "o caso do dinheiro revelou uma analogia muito real à do trabalho e à da terra. A aplicação da ficção da mercadoria a cada um deles levou à sua inclusão efetiva no sistema de mercado" (Polanyi 1980:195). Contudo, a estrutura fundiária é fundamental para o processo de geração de renda, pois, está alicerçada em padrões tradicionais e culturais sendo organizada como forma a permitir que os conhecimentos acumulados venham a serem utilizados.

Desta forma, ao desenvolver padrões próprios de geração de renda, é formatado uma lógica própria onde são desenvolvidas as atividades econômicas que são observadas apenas naquele contexto específico, nunca sendo replicado para outras sociedades, pois, os hábitos e a cultura são conformados por fatores intrínsecos a cada grupamento social específico, e, tendo a terra como meio do desenvolvimento destes. Nesta mesma perspectiva, o trabalho familiar também é utilizado para a reprodução social e fixação de hábitos e costumes construídos socialmen- te, sendo este o principal fomento das atividades culturais, religiosas e esportivas desenvolvidas no meio em questão. O trabalho das famílias é utilizado para dar suporte à realização de diversas atividades, fugindo especificamente do contexto produtivo, sendo estas responsáveis pelo desejo de continuar sendo camponês.

\section{MATERIAIS E MÉTODOS}

O método da pesquisa se baseou na aplicação de questionários semiestruturados e aplicados particularmente em três recortes diferentes, onde se configuram realidades diferenciadas de reordenamento agrário.

Recorte 1 - Famílias de Posseiros sem a titulação da terra: este recorte é formado por agricultores posseiros de uma área denominada povoado Boa Vista dos Pinhos no município de Presidente Juscelino - MA. Este povoado é formado por 62 (sessenta e duas) famílias de agricultores tradicionais que desenvolvem atividades agrícolas utilizando a tecnologia de corte e queima. O principal produto dessa economia é a farinha de mandioca e a juçara. Neste contexto, foram entrevistadas 8 (oito) famílias de agricultores, totalizando aproximadamente $13 \%$ (treze) do total de famílias residentes na comunidade. Durante a realização da pesquisa de campo também foram realizadas visitas às áreas de produção com a finalidade de conhecer os sistemas produtivos, as variedades e espécies de plantas e animais criados, a tecnologia adotada e também as formas utilizadas para o beneficiamento e comercialização da 
produção obtida, sendo observados elementos de organização social da produção e gestão territorial da comunidade.

Recorte 2 - Famílias de Quilombolas, tendo a área reconhecida e não homologada: este recorte se refere à comunidade de Juçaral dos Pretos no município de Presidente Juscelino - MA, esta comunidade já foi reconhecida pela Fundação Cultural Palmares como comunidade quilombola, apesar de ainda não ter sido homologado o processo definitivo de titulação. A população é formada por 48 (quarenta e oito) famílias de quilombolas que desenvolvem atividades econômicas baseadas na agricultura de corte e queima de forma tradicional. Em Juçaral dos Pretos foram aplicados 10 (dez) questionários totalizando aproximadamente $27 \%$ (vinte e sete) das famílias quilombolas.

Recorte 3 - Famílias de Quilombolas que foram inseridas dentro do contexto formal de reforma agrária: este recorte é formado por quilombolas que tiveram o seu território tradicional regularizado sob a forma de reforma agrária do Governo do Estado do Maranhão.

Nesta área foram aplicados dez questionários semiestruturados junto à sociedade local e feitas observações coletadas no processo de observação participante que contribuíram para coleta e compreensão das informações. Durante o processo, ficou claro que a influência dos agentes externos tem transformado as relações internas, quebrando laços historicamente construídos e implementando novas formas de produção, cultivo e (des)organização social, diminuindo assim, as relações com as pessoas e também com a natureza viva, tornando esta dispensável para a vida destas famílias. Estes recortes foram eleitos por serem as principais formas de disposição das famílias no território Lençóis Munim, conforme descritos anteriormente, e esta realidade se estende para todo o estado do Maranhão, que possui boa parte de suas terras ocupadas por posseiros, assentamentos estaduais, federais, crédito fundiário ou cédula da terra, e também apresenta expressivo número de áreas de ocupação tradicional por remanescentes de quilombos que já foram ou estão tendo o seu processo de reconhecimento efetivado pela Fundação Cultural Palmares.

Os questionários utilizados foram construídos observando a metodologia dos sistemas agrários, e traz uma complexidade de informações muito grande, muitas vezes fugindo dos padrões tradicionais desenvolvidos pelas sociedades pesquisadas, complexificando ainda mais a leitura dos dados e posterior análise dos mesmos.

\section{DISCUSSÃO}

\section{A TECNOLOGIA DE ROÇA E QUEIMA}

As formas de obtenção da produção e a tecnologia utilizada no desenvolvimento da agricultura precedem a distinção das formas de transformação de produção em renda, desta maneira, é necessária uma caracterização da for- 
ma de associação entre trabalho e terra para a obtenção de capital (financeiro ou não).

Para Damasceno Júnior (2010), a abertura da mata para a implantação de roças é uma técnica adotada pelos agricultores há muitos anos, primeiramente eles retiram a vegetação nativa, derrubando a floresta, seguida da queima das árvores que não foram retiradas para a implantação das lavouras. Após dois ou três ciclos de cultivo a área é abandonada, e a cada novo ciclo os agricultores adentram a mata para realizarem as mesmas operações, caracterizando a inerência do sistema.

\section{PRODUÇÃO COMERCIALIZADA}

A produção destinada ao mercado assume diferentes papéis e funções em cada contexto estudado por este trabalho, visto que, embora os contextos culturais se assemelham em função da proximidade física das comunidades estudadas a forma de organização social é diversa e influenciada sobremaneira pela forma de reordenamento agrário utilizado.

Recorte -1 : No primeiro recorte observamos um nível de insegurança latente e peculiar às famílias pesquisadas. A não solução da questão fundiária estimula uma diversificação maior da produção e um desejo bem grande de substituição dos padrões tradicionais de produção agrícola, mas, paradoxalmente a especialização do trabalho fez com que estas famílias desenvolvessem uma diferenciação na forma de produção de farinha, que tem como matéria-
- prima a mandioca, que é produzida ainda utilizando a tecnologia de roça e queima, bem peculiar a todas as comunidades rurais. A questão torna-se ainda mais complexa quando é observado que a especialidade adquirida garante uma diferenciação positiva no preço da farinha, fazendo com que esta insegurança se transforme em frustração, pois, mesmo com os preços atraentes da farinha, isso não se refere ao ganho econômico real, em virtude, principalmente, das respostas negativas do solo em se tratando de produtividade, não podendo assim, atender às demandas e necessidades apresentadas pelos mercados.

A solução encontrada pelas famílias de posseiros foi a utilização de espaços menores com outros tipos de produtos que também são demandados pelos mercados. Dentre os produtos, encontramos o coentro, a cebolinha, a abóbora, o quiabo e o maxixe, destinados ao consumo e à comercialização, e ainda uma pequena produção de frango geneticamente melhorado. Estas práticas caracterizam a transição do sistema tradicional de produção para um sistema onde são utilizadas outras tecnologias. Durante o processo de observação participante também foi notada uma relação de respeito e preservação do meio físico, pois, dele depende também uma importante fonte de renda da sociedade de Boa Vista dos Pinhos, a produção de juçara.

Ficou claro que os agricultores pesquisados já perceberam que preservando os igarapés, as juçareiras irão continuar a produzir e garantir mais uma fonte de renda para essas famílias. A preser- 
vação dos padrões culturais também passa pelo consumo de juçara, visto que, além de consumir e comercializar, o líquido extraído da juçareira, é responsável pela manutenção das relações de parentesco e compadrio. Dentro das práticas de transição dos sistemas tradicionais para sistemas mais eficientes do ponto de vista econômico foi observado que algumas famílias vêm adotando técnicas diferenciadas de beneficiamento da juçara, como as despolpadoras elétricas, servindo como forma de diminuição da penosidade do trabalho e aumento da capacidade de geração de renda.

Recorte - 2: A produção comercializada pelos quilombolas de Juçaral dos Pretos é formada pelo excedente da produção destinada ao consumo familiar, desta forma, todos os produtos disponíveis possuem uma característica identitária muito forte. A relação com o mercado se dá principalmente quando outras sociedades se aproximam do quilombo, e percebem neste, um potencial produtor de alimentos e produtos culturais. Estes produtos são centrais na manutenção do meio de vida daquelas famílias. Dialeticamente, esta relação é construída de fora para dentro da comunidade, fazendo construir um processo de apropriação continuada por parte das outras sociedades das culturas e tradições próprias da comunidade de Juçaral dos Pretos, assim, quando a farinha produzida no quilombo é consumida, é também consumida e aceita pelas outras sociedades a realidade adotada naquela sociedade, de maneia que, não existem produtos produzidos destinados ao mercado, muito pelo contrário, as demandas são externas e muita das vezes até rechaçadas pelos quilombolas de Juçaral dos Pretos, desta forma, a política de reconhecimento das comunidades de Juçaral dos Pretos como área quilombola é perfeitamente entendida e validada, carecendo agora da titulação definitiva da área em questão. Nesta perspectiva, a consolidação do processo será responsável pelo fortalecimento dos padrões produtivos peculiares que tanto são demandados pelas outras sociedades. A farinha de mandioca, principal produto comercializado não passou por nenhum tipo de transformação para atender às demandas do mercado, continua sendo produzida em barracões de taipa com fornos de ferro aquecidos com lenha retida das capoeiras próximas. A tradição alimentar do quilombo de Juçaral dos Pretos garante a essa comunidade a ampliação do plantel de aves, dentre elas, galinhas caipiras, patos e marrecos, que são criados nos fundos de quintal, denominados terreiros, e são alimentados de milho produzido na roça de toco junto com a mandioca, assim, pode-se imaginar que Juçaral dos Pretos não produz renda monetária fruto da produção, mas, ao chegarmos à comunidade e entrevistar os quilombolas percebemos outro produto comercializado, a cultura quilombola, que é expressa por meio das festas e festejos, atraindo centenas de pessoas da região, transformando-se na maior fonte de receita desta comunidade.

Recorte - 3: Possuindo uma complexidade bem maior que os dois sistemas analisados anteriormente, o Assenta- 
mento Folhal diferencia-se, primeiro, por se tratar de uma comunidade quilombola, e segundo, observando a forma como o Estado promoveu a política de reordenamento agrário. A comunidade de Folhal, hoje é um assentamento de reforma agrária, com lotes coletivos sendo utilizados de acordo com os contratos verbais firmados entre as famílias. A infraestrutura habitacional também foi viabilizada durante o processo de transformação do quilombo em assentamento.

Com a chegada das políticas públicas, houve um processo de individualização da sociedade, onde as demandas, antes coletivas, foram transformadas e atreladas aos recursos e programas governamentais.

A discussão produtiva relacionada diretamente à infraestrutura e assistência técnica deu lugar às demandas de projetos produtivos e substituição total das roças de toco por campos agrícolas mecanizados, buscando o aumento da escala de produção.

Tudo o que é produzido é para o atendimento das demandas externas da comunidade, a farinha produzida é praticamente toda destinada ao mercado, as questões ambientais como a conservação da água e da terra foram esquecidas, uma vez que, a priorização é por aumento da produção que vai gerar mais renda monetária àquela sociedade, em função disso, boa parte das referências tradicionais foram perdidas ou estão se perdendo, a relação com o meio físico diminuiu, e principalmente a capacidade de organização e superação dos problemas está sendo erodida.

\section{PRODUÇÃO DESTINADA AO AUTO- CONSUMO}

$\mathrm{Na}$ maioria das vezes o entendimento de produção para autoconsumo se restringe aos alimentos, e isso não é verdade, pois, existe uma quantidade bastante grande de produtos e serviços que são produzidos e consumidos pelas sociedades rurais, especificamente as populações contextualizadas neste estudo.

Estes produtos são alimentos, serviços ambientais, serviços culturais, passando por utensílios para o trabalho cotidiano e para a satisfação de inúmeras necessidades apresentadas pelas famílias, assim, apresentando uma cisão entre rural e agrícola, visto que, no meio rural são produzidos e consumidos também produtos de natureza não agrícola e que são fundamentais para a preservação dos meios de vida das famílias, capazes de gerarem outras rendas além da renda monetária.

A produção de alimentos para o consumo das famílias do povoado Boa Vista dos Pinhos é bastante diversificada, sendo composta por produtos que fazem parte da dieta alimentar das famílias de agricultores, perdendo seu significado específico. Esta produção é obtida por meio de práticas de produção agrícola, criação de pequenos animais e extrativismo vegetal, todas obtidas utilizando as tecnologias tradicionais de roça e queima, criação de fundo de quintal e extrativismo, todas as atividades são desenvolvidas em escalas pequenas. A base da alimentação das famílias de agricultores posseiros de Boa Vista dos Pinhos é a farinha 
de mandioca, produto que se destaca tanto na comercialização quanto no consumo, apresentando grande importância para a geração de renda na comunidade. A transformação sofrida ao longo dos anos na qualidade da farinha produzida em Boa Vista dos Pinhos também fora incorporada pela sociedade local, assumindo uma importância tal que, todos os agricultores pesquisados produzem mandioca para transformar em farinha, com o objetivo de alimentação humana.

Dentre as famílias pesquisadas todas consomem juçara, este fato se constitui em um hábito cultural dos moradores de Boa Vista dos Pinhos, mas, nem todas possuem capacidade de praticar o extrativismo da espécie, pois, esta prática demanda de habilidades físicas específicas para subir na juçareira para coletar o fruto e o transformar em vinho, posteriormente.

No contexto específico da pesquisa, $60 \%$ dos agricultores desenvolvem esta atividade, caracterizando como renda de autoconsumo gerada, durante os meses de outubro a janeiro. $\mathrm{O}$ extrativismo também é observado em espécies vegetais endêmicas na região, como a manga de foice e o caju. Estas espécies são encontradas com muita frequência ao longo de toda a comunidade, fazendo com que as famílias de agricultores utilizem seus frutos como complemento da sua dieta durante a safra.

Um fato peculiar que chamou atenção foram as mudanças climáticas que já começam a serem notadas pelas famílias de agricultores, pois, os mesmo se referem com muita frequência às mudanças no calendário de produção de diversos frutos e frutas, interferindo de forma significativa nos meios de vida das famílias de agricultores, essas mudanças ocorrem por meio da quebra de tradições culturais, como é o caso dos produtos à base de milho, que eram consumidos durante a Semana Santa, que, não vai mais ser possível, em função do atraso do calendário de plantio. O milho, além de produzir pratos típicos e bolos, também é consumido in natura pelas famílias de agricultores, o destino de boa parte da produção deste grão é a alimentação de pequenos animais que são criados nos fundos dos quintais, como forma de suprir as necessidades de consumo de proteína animal.

No quilombo de Juçaral dos Pretos, a produção agrícola é muito mais diversa do que nas outras duas sociedades pesquisadas, este fato pode ser explicado observando que, do ponto de vista agrícola, existe uma autonomia produtiva muito forte em função principalmente da manutenção dos hábitos culturais, refletidos nesta discussão pela alimentação das famílias em questão. O comércio local é formado basicamente de uma pequena cantina onde são oferecidos produtos que não podem ser produzidos pelas sociedades locais, dentre esses produtos são comercializados o sabão, o macarrão, óleo de soja, refrigerantes e biscoitos, elementos que começam a impactar na realidade da formação da dieta destas famílias, não caracterizando uma dependência ao capital financeiro. Neste comércio também são vendidos o ar- 
roz, o feijão e o milho, além de bebidas alcoólicas que são adquiridas por meio da renda monetária conseguida junto aos programas de transferência de renda e seguridade social destinadas a estas famílias de quilombolas.

Mas a realidade da compra de produtos básicos é bastante distante na comunidade, este processo de substituição da produção agrícola pela compra dos mesmos no mercado não se constitui uma realidade objetiva, podendo ainda serem bastante influenciados por políticas públicas, inclusivas de fomento às atividades tradicionais de produção. Um caso bem característico dessa discussão refere-se à produção de arroz, observando que, as suas limitações produtivas são ocasionadas por problemas edáficos e climatológicos, e mesmo assim, 70\% das famílias pesquisadas ainda praticam o cultivo do arroz, configurando-se em um importante elemento na composição da renda das famílias de agricultores, uma vez que o mesmo produto tem uma importância cultural reconhecida. O milho, cultura fundamental na manutenção da identidade dos quilombolas é cultivado por $60 \%$ dos agricultores do povoado, sendo utilizado basicamente para subsidiar a criação de porcos, atividade desenvolvida por 3 entre os 10 agricultores pesquisados, e de galinhas caipiras, criadas por $30 \%$ das famílias de agricultores pesquisados, que são consumidas na própria comunidade. No contexto de consumo dos produtos agrícolas, a farinha, mais uma vez, assume o protagonismo do processo, uma vez que, 100\% das famílias pesquisadas produzem farinha para o consumo próprio, sendo este fato marcante, pois, como já foi discutido em outro momento deste trabalho, a produção de farinha envolve uma quantidade expressiva de elementos e percepções por parte dos agricultores, sendo mais forte ainda no quilombo de Juçaral dos Pretos.

Em função da importância da farinha para a economia local, existe uma preocupação bem grande com a preservação das fontes de água, pois, são nestes balneários que ocorre o processo de fermentação da raiz de mandioca.

Dentro desta perspectiva surgem algumas preocupações referentes às condições higiênicas e sanitárias do processo. O mesmo local onde as raízes são fermentadas, a sociedade local utiliza para lavar roupas, louças, tomar banho, banhar e matar a sede de animais de carga, além dos porcos que frequentam estes logradouros.

As fruteiras endêmicas, como o caju, são utilizadas na época da safra para complementar a alimentação dos quilombolas, pois, cerca de 70\% das famílias se valem destas fontes de recursos para terem a sua soberania alimentar preservada. A manga aparece em um contexto muito parecido com o caju, sendo que, dentro de um universo de 10 famílias pesquisadas, 6 famílias declaram que tem na coleta da manga uma atividade complementar ao cardápio e na geração de renda de autoconsumo.

No contexto geral, já começam a aparecer agricultores que buscam outras atividades produtivas fora das práticas tradicionais, como é o caso de uma família que começa a desenvolver a 
criação de bovinos destinada ao corte, para o consumo na comunidade, não se configurando assim, como uma atividade apenas de autoconsumo, mas, uma atividade que gera excedente de produção para o mercado.

A produção de ovos na comunidade é decorrente ao processo de reprodução das galinhas destinadas à criação para o abate, mesmo assim, ainda são retiradas algumas dúzias para a complementação do cardápio diário das famílias de agricultores, portanto, não existe uma produção de ovos destinada à alimentação dos quilombolas.

No assentamento de Folhal, a produção agrícola tem uma importância menor se comparada às outras realidades pesquisadas, pois, grande parte do que é consumido advém de aquisição em quitandas localizadas dentro da área do assentamento. Não existe dúvida que há uma diversificação bem maior da produção de alimentos, mas, esta diversificação não é significativa, pois, as quantidades produzidas são muito pequenas, não sendo suficientes para atenderem as necessidades nutricionais das famílias assentadas. Existem, no assentamento Folhal, atividades de fundo de quintal que remetem a uma nova fase de estruturação dessa sociedade, visto que as roças de toco foram praticamente esquecidas e são poucos os assentados que ainda as desenvolvem.

Um fato que chamou muito a atenção durante o processo de observação participante foi que, as trocas de diárias (empréstimos de dias trabalhados) e troca de sementes desenvolvidas, muito comum nas outras realidades, são bem raras de acontecerem em Folhal, as reuniões para discutir os problemas do assentamento são cada vez menos frequentes, e que está em curso um processo de individualização desta sociedade, principalmente, naquelas famílias que foram atendidas por diferentes políticas públicas.

É latente o fato de que as políticas públicas destinadas a este assentamento específico chegam a quantidades insuficientes, fato que pode explicar o fenômeno da individualização das atividades econômicas e o enfraquecimento das estruturas organizativas do assentamento de Folhal. A produção da roça tradicional ainda é significativa, mas bem inferior quantitativamente das realidades anteriormente descritas, um produto que chama atenção para essa realidade é o arroz, que apesar de ser cultivado por $80 \%$ das famílias pesquisadas, não é suficiente para atender as necessidades alimentares, carecendo complementar essa quantidade com o arroz encontrado no armazém do assentamento. A produção de milho está diretamente associada à produção de frangos, pois, este grão é destinado basicamente à alimentação destes animais, mostrando uma mudança na matriz e direcionando a produção para o mercado externo, fato este que faz com que as famílias do assentamento possam galgar algum nível de desenvolvimento econômico, mas, por outro lado, a desagregação social é muito marcante nesta sociedade. Apenas duas famílias pesquisadas $(20 \%)$ desenvolvem o cultivo do feijão, ratifica que em outras épocas era mais frequente, fazendo com que a maior 
parte do produto consumido venha dos mercadinhos e quitandas localizadas no assentamento. Não diferente da realidade observada nos recortes anteriores, a produção de farinha destinada à alimentação das famílias do assentamento Folhal é significativa, fazendo com que esta atividade seja de extrema importância para a segurança e soberania alimentar da sociedade local.

A quantidade consumida é significativa, visto que, o consumo da farinha está associado a diversos tipos de alimentos que compõem a dieta desta sociedade. Inicialmente, ao amanhecer o café é tomado com farinha, nos intervalos, as frutas como a manga são comidas com farinha, a juçara é tomada com farinha, no almoço, qualquer prato que venha ser servido é consumido com uma quantidade significativa de farinha, e assim se estendendo por todo o cotidiano dessas famílias.

Esta realidade também é observada nos dois recortes anteriores, a manga, o caju e a juçara apesar de serem produtos sazonais assumem uma importância fundamental na renda de autoconsumo das famílias do assentamento, pois, são consumidas nos intervalos das refeições fazendo com que haja um complemento nutricional, melhorando a qualidade da dieta destas famílias.

As safras ocorrem em períodos diferentes do ano, fazendo com que sempre esteja disponível um destes produtos para alimentar as famílias dos assentados de Folhal, perdendo a importância ao mesmo tempo em que ocorre a desagregação social.
Os suínos, ainda são criados de forma muito artesanal, provocando problemas sociais graves, como a invasão desses animais nas roças de mandioca dos vizinhos. Estes animais são produzidos observando a lógica do consumo de proteína animal por parte das famílias de assentados. Destes animais é consumida a carne fresca, alguns pedaços são salgados para serem adicionados ao feijão, e outros transformados em toicinho que podem ser consumidos fritos, colocado no arroz ou no feijão. Desta forma, a produção destinada ao autoconsumo das famílias do assentamento Folhal é bastante diversificada e assumem vários papéis. Com a abertura social para a aplicação de políticas públicas de desenvolvimento, as questões de identidade são bastante afetadas, fazendo com que sua importância venha ser diminuída.

Observou-se que no assentamento Folhal está sendo desenvolvida uma política de crédito agrícola, o PRONAFA, cujo objetivo principal é a substituição da tecnologia tradicional de roça e queima por outra dita moderna, mas, o método utilizado é questionado, principalmente observando o conhecimento das famílias do processo que está sendo implantado.

Para isso, foi construída uma infraestrutura produtiva na comunidade, que, sem dúvidas nenhuma, não é capaz de atender as novas demandas apresentadas pelas tecnologias, uma dessas demandas é o aumento do número de capinas influenciado pelo afloramento do banco de sementes após o revolvimento inicial do solo durante as etapas iniciais do processo. 
Desta forma, criar um novo problema para as famílias de assentados e não proporcionar métodos para a solução dos já existentes não se configura em momento nenhum uma estratégia de desenvolvimento rural.

\section{RENDA MONETÁRIA}

Geralmente, a literatura trata a renda monetária como aquela obtida por meio da venda de produtos e mão de obra por parte das famílias de agricultores. Neste trabalho buscou-se ir além desta abordagem convencional, contabilizando outras fontes de entrada de recursos financeiros na Unidade Familiar de produção.

Recentemente, o governo do Brasil, por meio de programas de redistribuição de renda, vem destinando quantitativos monetários mensais às famílias que mantêm seus filhos na escola, política também desenvolvida no meio rural. Este processo tem sido responsável pelo aumento da entrada de capital financeiro, e consequente elevação dos níveis de consumo das famílias de agricultores.

Assim, com a elevação da renda, as famílias de agricultores têm tido acesso a bens duráveis de consumo, principalmente eletrodomésticos e motocicletas, que possibilitam a diminuição da penosidade e elevam a qualidade de vida desta população. Em se tratando de agricultores tradicionais, esta discussão induz a algumas reflexões como, por exemplo, a de que, com a diminuição dos recursos naturais, base de insumos da população tradicional, os programas de transferência de renda têm servido para garantir a sobrevivência destes povos, muito distante de observações pontuais que induzem a avaliações preconceituosas como, por exemplo, aquelas que falam que os programas sociais têm contribuído para a criação de uma geração de preguiçosos.

$\mathrm{Na}$ comunidade de Boa Vista dos Pinhos, sete famílias pesquisadas recebem o valor de $\mathrm{R} \$ 2$ 298,00 (duzentos e noventa e oito reais) mensais do programa Bolsa Família, correspondendo a um total anual de $\mathrm{R} \$ 3.576,00$, muito significativo para estas famílias de agricultores. As transferências sociais estão restritas aos programas Bolsa Família e a aposentadoria por idade, se constituindo em um elemento muito importante na formação da renda das famílias. Dentre as famílias pesquisadas, as maiores rendas estão nas famílias de aposentados. Um aposentado recebe anualmente $\mathrm{R} \$ 9.384,00$. A média de repasse feita por família pelo programa Bolsa Família corresponde a R \$ 3.552,00/ano.

As atividades comunitárias e culturais também são consideradas rendas financeiras pelas famílias do povoado de Boa Vista dos Pinhos, neste contexto específico estas rendas correspondem a rendas diversas, e estão presentes na composição monetária de seis entre oito famílias pesquisadas. A venda da força de trabalho também é importante na composição final da renda das famílias pesquisadas, pois, está presente em seis das oito famílias.

No quilombo de Juçaral dos Pretos não existe venda de diárias, e sim troca de 
dias trabalhados, o nível de organização implementa uma dinâmica própria de troca de força de trabalho, baseados em princípios de reciprocidade. A venda de diárias é feita para fora da comunidade, muitas vezes em atividades ligadas a outras atividades não relacionadas às práticas agrícolas, como serviços de marcenaria e construção civil. Estas receitas são responsáveis por um percentual significativo na formação da renda final, chegando a corresponder a 18\% (dezoito por cento) do total. Nesta comunidade também é premente as receitas oriundas das transferências de renda por meio da Bolsa Família, visto que, 9 (nove) das 10 (dez) famílias pesquisadas recebem a subvenção do Estado Brasileiro. Os valores também correspondem aos valores repassados nos outros dois recortes pesquisados. No contexto representado, quatro famílias recebem aposentadoria, tendo apenas um dos membros da família aposentado.

O Assentamento Folhal é marcado por contradições relacionadas à formação da renda, neste aspecto, é notada a desarticulação social e uma individualização, porque os princípios de coesão social foram rompidos pela criação do assentamento. As rendas não agrícolas correspondem ao significativo percentual da receita total, quando observado os percentuais acrescidos pelo programa de transferência de renda e aposentadorias. As trocas de diárias são cada vez menos frequentes, existindo casos de vendas de dias trabalhados, principalmente para aquelas famílias que possuem pessoas empregadas e aposentados rurais. Nas atividades comunitárias e culturais o processo de obtenção de renda está estagnado e as organizações promotoras da integração das famílias não têm representatividade política necessária para exercer o seu papel. Em Folhal começa a surgirem atividades econômicas ligadas a outros serviços como, por exemplo, a venda de produtos cosméticos e acessórios de beleza.

\section{A RENDA FINAL}

Para fins deste trabalho, é considerado renda final o somatório da renda da comercialização, a renda dos produtos consumidos e a renda oriunda de atividades não agrícolas.

A renda final em área de posseiros sem a titulação da terra: no primeiro recorte é observada uma variação grande na renda das famílias pesquisadas, indo de $\mathrm{R} \$$ 688,00 a $\mathrm{R} \$ 45.489$ anuais, estando concentrada em uma faixa intermediária entre $\mathrm{R} \$ 20.000,00$ e $\mathrm{R} \$ 30.000,00$. A maior parte da renda destas famílias advém das transferências sociais seguidas pela venda de produtos de origem agrícola, mais especificamente da farinha de mandioca, seguida pela renda de autoconsumo e por último a renda da venda da força de trabalho.

Tabela 1 - Representação Gráfica da composição da renda final em área de posseiros sem a titulação da terra

\begin{tabular}{c|c|c|c|c} 
& Consumida & Comercializada & $\begin{array}{c}\text { Força de } \\
\text { Trabalho }\end{array}$ & Total \\
\hline Família 1 & 3.150 & 6.300 & 9.822 & 19.272 \\
Família 2 & 4.500 & 1.870 & 8.211 & 14.581 \\
Familia 3 & $6.457,70$ & 6.510 & 9.600 & $22.567,70$ \\
Familia 4 & 4.720 & 12.425 & 28.344 & 45.489 \\
Familia 5 & 6.562 & 10.500 & 12.664 & 29.726 \\
Familia 6 & 5.400 & 16.800 & 4.012 & 26.212 \\
Família 7 & 96 & 192 & 400 & 688 \\
Familia 8 & 15.340 & 4.200 & 600 & 20.140 \\
\hline
\end{tabular}

Fonte: Pesquisa de Campo (2015). 
Gráfico 1 - Representação Gráfica da composição da renda final em área de posseiros sem a titulação da terra

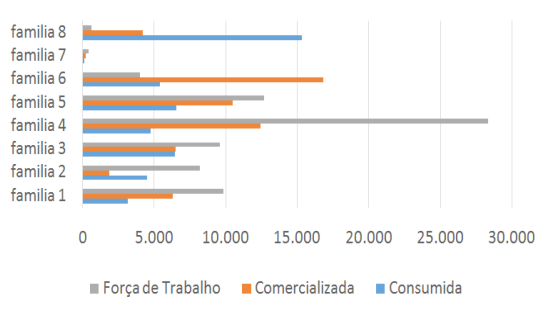

Fonte: Pesquisa de Campo (2015).

Renda final entre famílias de quilombolas, tendo a área reconhecida como quilombo, mas não homologada: no segundo recorte existe uma uniformidade bem maior na variação da renda final indo de $\mathrm{R} \$ 10.830,00$ a 24.260,00, ficando concentrada na faixa de R\$15.000,00, mostrando uma desigualdade pequena. A maior parte da renda produzida no quilombo de Juçaral dos Pretos é destinada ao abastecimento das necessidades das famílias, seguida da renda originada da venda da força de trabalho e por último da renda obtida pela venda de produtos da agricultura e do beneficiamento da produção.

A maior renda é obtida junto à família que mantem as atividades de venda de farinha muito ativas, não se restringindo apenas ao comércio do que é produzido, mas, também desenvolvendo atividades de atravessador da produção agrícola. A menor renda também vem de famílias que desenvolvem atividades de comercialização de farinha, mas, o diferencial está onde não é observada a presença de atravessadores, neste caso, a farinha é comercializada na própria comu- nidade para quem tem interesse em adquirir o produto, caracterizando um sistema incompleto e desorganizado do ponto de vista do desenvolvimento.

Tabela 2 - Renda final entre famílias de Quilombolas de Juçaral dos Pretos

\begin{tabular}{c|c|c|c|c} 
& Consumida & Comercializada & $\begin{array}{c}\text { Força de } \\
\text { Trabalho }\end{array}$ & Total \\
\hline Família 1 & $5.717,50$ & 2.200 & 5.316 & 13.233 .50 \\
Família 2 & 7.230 & 10.500 & 2.700 & 20.430 \\
Família 3 & 5.185 & 2.100 & 10.120 & 17.405 \\
Família 4 & 4.530 & 2.100 & 9.540 & 16.170 \\
Família 5 & 6.970 & 4.200 & 2.304 & 13.474 \\
Família 6 & 5.940 & 16.800 & 1.520 & 24.260 \\
Família 7 & 9.800 & 8.400 & 2.980 & 21.180 \\
Família 8 & 5.135 & 700 & 9.700 & 15.535 \\
Família 9 & 3.890 & 6.700 & 240 & 10.830 \\
Familia 10 & 2.060 & 700 & 9.900 & 12.660 \\
\hline
\end{tabular}

Fonte: Pesquisa de Campo (2015).

Gráfico 2 - Renda final entre famílias de Quilombolas de Juçaral dos Pretos

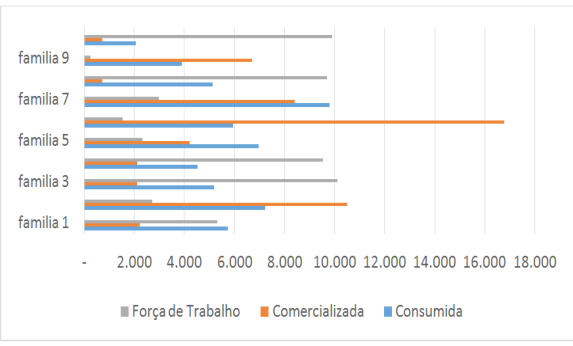

Fonte: Pesquisa de Campo (2015).

Renda final entre as famílias de quilombolas, tendo a área reconhecida como assentamento de reforma: as atividades não agrícolas correspondem ao grande percentual na formação de renda final das famílias, seguida de atividades de autoconsumo e em terceiro lugar estão os produtos comercializados. Pode-se observar que a produção agrícola que gera receita é tida como atividade secundária, sendo desenvolvida em pequenas áreas e muitas vezes por meio da aquisição da força de trabalho das famílias que não possuem empregos. 
As tradições e práticas agrícolas tradicionais deram espaço a outras práticas que demandam pouca força e trabalho, fazendo com que diminua a importância destas atividades no cotidiano familiar. As principais atividades que compõem a renda final estão ligadas aos empregos públicos e às aposentadorias rurais, desenvolvidas fora dos domínios físicos do assentamento.

Tabela 3 - Renda Final entre os Assentados de Folhal

\begin{tabular}{|c|c|c|c|c|}
\hline & Consumida & Comercializada & $\mid \begin{array}{ll}\text { Força } & \text { de } \\
\text { Trabalho } & \end{array}$ & Total \\
\hline Familia 1 & 5.200 & 2.550 & 2.400 & 10.150 \\
\hline Familia 2 & 8.650 & 1.650 & 12.212 & 22.512 \\
\hline Familia 3 & 10.860 & 2.250 & 3.228 & 16.338 \\
\hline Familia 4 & 2.160 & & 10.898 & 13.058 \\
\hline Familia 5 & 7.980 & 2.700 & 5.280 & 15.960 \\
\hline Familia 6 & 3.285 & 7.400 & 3.872 & 14.557 \\
\hline Familia 7 & 4.414 & 15.000 & 3.000 & 22.414 \\
\hline Familia 8 & 8.156 & 986 & 3.880 & 13.022 \\
\hline Familia 9 & 6.950 & & 11.958 & 18.908 \\
\hline Familia 10 & 5.985 & 750 & 700 & 7.435 \\
\hline
\end{tabular}

Fonte: Pesquisa de Campo (2015).

Gráfico 3 - Renda Final entre os Assentados de Folhal

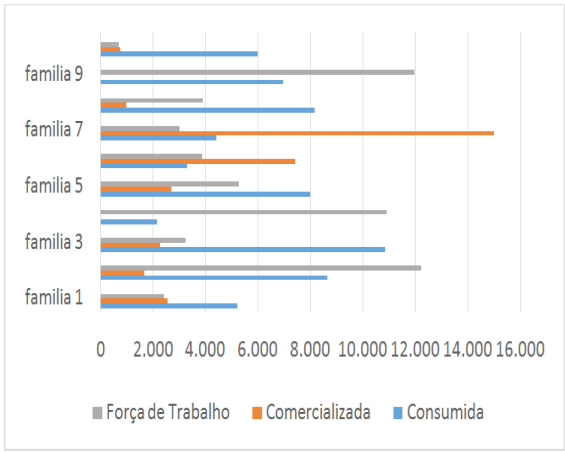

Fonte: Pesquisa de Campo (2015).

Comparação entre a formação da renda final entre os três recortes estudados: a representação gráfica a seguir trata das rendas finais nos três recortes estudados por este trabalho de pesquisa. A partir destas análises é observada que existem profundas diferenças na conformação da renda dependendo da política de reordenamento agrário implementada. A maior variação ocorre no recorte 1 , a falta de políticas públicas permite que regras próprias venham ser criadas, fazendo com que, este processo desregulamentado, venha atender as aspirações de quem possui os meios de produção, ou seja, reprodução da lógica capitalista, onde o principal veículo de desenvolvimento rural é o dinheiro gerado pela produção de farinha.

No recorte 2, ou seja, no quilombo de Juçaral dos Pretos, existe uma pequena diferenciação no padrão da renda entre as famílias pesquisadas, fazendo com que as práticas sociais tenham capacidade de reprodução, visto que, as necessidades apresentadas pelas famílias de agricultores estão sendo atendidas pela economia desenvolvida internamente no quilombo, apresentando um grande diferencial, as atividades culturais, que neste contexto se tornam importantes.

No assentamento Folhal o principal elemento de diferenciação das rendas geradas não é o valor monetário, e sim a natureza da atividade desenvolvida. Dentre aqueles que praticam a agricultura, a renda é muito baixa, visto que, os produtos não são comercializados por falta de escala, e isto acarreta em uma pequena demanda. As rendas mais elevadas são formadas dentro das famílias que possuem empregos ou aposentadorias. 
Gráfico 4 - Comparativo da renda nas três realidades pesquisadas

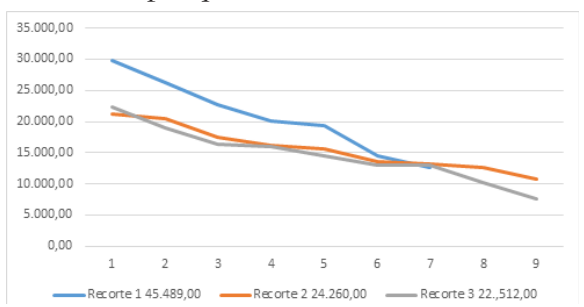

Fonte: Pesquisa de Campo (2015).

\section{CONSIDERAÇÕES FINAIS}

A estrutura fundiária é determinante para o processo de geração de renda nas comunidades pesquisadas, pois, esta garante a forma de utilização e transformação dos recursos naturais em renda monetária.

O desenvolvimento das atividades econômicas também recebe influência pelos recortes agrários diferenciados, uma vez que, depende do trabalho, o principal fomento destas economias. O trabalho pode ser vendido ou trocado na forma de dinheiro ou de unidades de trabalhos adicionais.

Cada comunidade pesquisada possui uma forma específica de organização social, fazendo com que cada recorte apresentado possua características peculiares, que podem ser expressas na tecnologia desenvolvida em Boa Vista dos Pinhos, a coesão social observada no quilombo de Juçaral dos Pretos ou as transformações e individualização das relações sociais observada no Assentamento Folhal.

Observou-se que a formação da renda passa por um processo de diversificação, não sendo a atividade agrícola como a maior responsável pela formação da renda final, passando por práticas de extrativismo e beneficiamento da produção, até por meio de programas sociais como a previdência social, que paga as aposentadorias até programas de transferência de renda como o Bolsa Família.

Outros produtos são gerados durante o desenvolvimento das atividades econômicas, geralmente, estas atividades são responsáveis por processos de reconhecimento social, reciprocidade e trocas, todos estes processos capazes de contribuirem para o incremento da renda financeira.

Dessa forma, é constatado o fato de que as atividades econômicas são responsáveis pela formação de valores sociais e não apenas valores monetários.

\section{REFERÊNCIAS}

Cuéllar, J. P. D. 1997. Nossa diversidade criadora: relatório da Comissão Mundial de Cultura e Desenvolvimento. Campinas: UNESCO, Ed. Papirus.

Damasceno Júnior, J. B. 2010. Impacto dos mercados institucionais na agricultura familiar no município de Zé Doca, Maranhão. Dissertação de Mestrado, Curso de Mestrado em Agroecologia, Universidade Estadual do Maranhão.

Marx, K., Easton, L. D. e Guddat, K. H. 1997. Writings of the Young Marx on philosophy and society. Indianápolis, EUA: Hackett Publishing.

Perroux, F. Ensaio sobre a filosofia do novo desenvolvimento. 1981. Lisboa: Fundação Calouste Gulbenkian. 
Polanyi, K. 1980. A grande transformação: as origens da nossa época. Rio de Janeiro, Campus.

Ramos, P. 2001. Propriedade, estrutura fundiária e desenvolvimento (rural). 2001. Estudos avancados 15(43): 141-156.

Sabourin, E. 2008. Marcel Mauss: da dádiva à questão da reciprocidade. Revista Brasileira de Ciências Sociais 23(66): 131-138.

Schneider, S. A. abordagem territorial do desenvolvimento rural e suas articulações externas. 2004. Sociologias 11: 88-125.

Recebido em 03/06/2017

Aprovado em 20/08/2017 